\title{
Grafismo, Multitemporalidad y Textos como Objetos de Poder en la Biografía de una Machi Mapuche en Chile
}

\author{
Graphism, Multitemporality and Texts as Objects of Power in the Biography of a \\ Mapuche's Machi in Chile
}

\author{
Ana Mariella Bacigalupo
}

\section{RESUMEN}

Las performatividades y biografías orales chamánicas de los Mapuche -algunas estructuradas como "biblias" que incluyen alfabetizaciones chamánicas - desempeñan un papel fundamental en la producción de historia indígena en el sur de Chile. En este artículo, explico cómo y por qué una machi mapuche mestiza me encargó que escribiera sobre su vida y práctica en forma de "biblia". Este libro se convertiría en un objeto ritual y en un medio para guardar su poder chamánico al textualizarlo y así permitirle hablar ante un futuro público. Las realidades y los poderes encerrados en su "biblia" podrían ser extraídos, transformados, divulgados y actualizados para variados fines, incluso para lograr el renacimiento chamánico. Por último, argumento que, a través del uso y la interpretación de este tipo de "biblia", los chamanes mapuche amplían sus conceptos académicos de historia y alfabetización indígenas.

Palabras Claves: Chamán, Texto, Biblia, Mestizo, Historia, Alfabetización, Mapuche.

\begin{abstract}
Mapuche oral shamanic biographies and performances — some of which take the form of "bibles" and involve shamanic literacies - play a central role in the production of indigenous history in southern Chile. In this article, I explain how and why a mixed-race Mapuche shaman charged me with writing about her life and practice in the form of such a "bible". This book would become a ritual object and a means of storing her shamanic power by textualizing it, thereby allowing her to speak to a future audience. The realities and powers her "bible" stored could be extracted, transformed, circulated, and actualized for a variety of ends, even to bring about shamanic rebirth. Ultimately, I argue, through their use and interpretation of this kind of "bible", Mapuche shamans expand academic notions of indigenous history and literacy.
\end{abstract}

Key Word: Shaman, Text, Bible, Mestizo, History, Literacy, Mapuche.

i Department of Anthropology, The State University of New York (SUNY), Buffalo. Correo-e: anab@buffalo.edu 
Francisca Kolipi,una machi (chamán) mapuche católica, analfabeta, de setenta años, me sorprendió ya en nuestro primer encuentro. La conocí en I991 en su casa, situada en la comunidad de Millali, cercana al pueblo de Quepe, en la región de la Araucanía, en el sur de Chile. Francisca, luciendo una prolija trenza de pelo gris cubierta por un pañuelo azul, me miró fijamente con curiosidad y su rostro moreno curtido por el clima quedaba surcado de arrugas mientras hablaba. "Eres champuria [mestiza] como yo pero piensas como Mapuche. La familia de tu mamá es de Argentina como la mía. Vas a soñar mucho. Voy a enseñarte las cosas de machi y me vas a ayudar a sanar. Serás mi nieta. $Y$ después vas a escribir una 'biblia' sobre mí y yo nunca moriré" (3 de noviembre de 1991). Las identidades múltiples y mutables de Francisca y la mía propia la llevaron a pensar que, si yo aprendía sobre su práctica chamánica a través de sueños y rituales, podía escribir un texto que la representara y pudiera mediar entre los órdenes mapuche y no mapuche. Quería que esta biografía tomara la forma de una "biblia", un texto sagrado que incluiría sus palabras divinas escritas en lugar de las de Dios, Jesús, los apóstoles o el demonio. Francisca veía su "biblia" como un potente objeto chamánico con una función performativa. Serviría para acumular y textualizar su poder, hacerlo circular a través del tiempo y del espacio y permitir la comunicación entre vivos $y$ difuntos.

Era la identidad de machi champuria mapuche de Francisca, experta en el control de la economía de la alteridad, lo que le permitía visualizar efectivamente la transformación de un texto sagrado no mapuche en un objeto imbuido de poder chamánico capaz de alterar temporalidades de muerte y renacimiento. Los Mapuche utilizan un sinnúmero de biblias como vehículo para la memoria y para fusionar diferentes corrientes de conocimiento sagrado. Las biblias luteranas conservaban los poderes de demonios y propietarios de tierras que destruían la moralidad y sociabilidad mapuche; las biblias católicas de los capuchinos y las protestantes de los anglicanos encerraban el poder de Dios y la magia de la alfabetización; las "biblias" místicas mapuche celebraban los rituales mapuche y una conciencia histórica y étnica alterna; y las machi soñaban con "biblias celestiales" que narrarían sus biografías en el cielo. Pero Francisca percibía su "biblia" como un objeto intertextual que vinculaba la biografía oral y la performatividad ritual con la alfabetización literaria y gráfica, y tenía la capacidad de transformar el mundo y el futuro. Si bien las palabras de Francisca se convertirían en un texto sagrado, la fuerza de estas palabras continuaría ejerciendo el poder chamánico y la capacidad de accionar de Francisca, incluso en su ausencia física. La "biblia" de Francisca también le conferiría el poder de hablar ante un futuro público.' Cuando los chamanes futuros fumaran y cantaran sobre las palabras transcriptas de Francisca, los poderes de estas palabras serían extraídos, transformados y utilizados para variados fines. Recobrar los poderes de Francisca en mi texto también podría además constituir la primera etapa en un rito de iniciación que llevaría al renacimiento de algunas de las cualidades del espíritu de Francisca en una nueva machi luego de su muerte. La "biblia" de Francisca perpetuaría, entonces, los conceptos mapuche de continuidad histórica a través del renacimiento espiritual, a la vez que extendería los conceptos mapuche de historia y alfabetismo.

Pueblos indígenas sudamericanos sin sistemas propios de escritura alfabética a menudo tienen conceptos de tiempo, historia y capacidad de accionar que difieren de los de la historiografía positivista (el concepto de que los documentos de archivo brindan datos objetivos sobre una temporalidad lineal racional ${ }^{2}$ ). Algunos académicos argumentan que muchos pueblos indígenas analfabetos contaban con sus propios sistemas precolombinos de inscripciones, que luego conectaron con el sistema alfabético europeo (Salomon y Niño-Murcia 20II). Otros sostienen que los indígenas utilizan los textos como objetos rituales poderosos independientemente de la manera occidental de leer y entender el alfabeto (Erikson 2004, Gow 1990, Guzman-Gallegos 2009, Platt 1992, Rappaport y Cummins 2012). Pero, ¿qué tipo de conciencia histórica y alfabetización perduraba en el humo de tabaco soplado por machi Francisca encima de una biblia católica para extraer su poder? ¿Y qué tipo de capacidad de accionar transformaría mi texto sobre la vida y el poder chamánico de Francisca en una "biblia" sagrada y en un objeto animado para ser usado en el futuro por chamanes a fin de llevar a cabo el renacimiento de Francisca y producir historia indígena? A fin de responder a estas preguntas, analizo los poderes y la historia de vida de Francisca recurriendo a las teorías de alteridad y raza; a debates sobre oralidad, 
alfabetismo y grafismo, sobre las relaciones entre objetos animados y fetichismo; a la genealogía de las "biblias" mapuche; y a teorías sobre temporalidad y sobre el proceso de recordar y olvidar. Comienzo con la adquisición del poder chamánico por parte de Francisca, que determinó su comprensión de la "biblia" que yo habría de escribir sobre su persona.

\section{LA ADQUISICIÓN DE PODER CHAMÁNICO AMBIGUO}

El 22 de mayo de 1960 el sur de Chile fue sacudido por el terremoto más devastador de la historia de la región que, a su vez, desató la potencia de las machi mapuche del trueno. En la comunidad rural de Millali, el espíritu de una machi del trueno llamada Rosa Kurin, del sur de la Argentina, cayó como un rayo sobre Francisca, de 39 años, y la poseyó para transformarla así en una machi."Se me cayó la guata”, me contó Francisca. "Me arranqué el chaleco y los zapatos. Estaba como loca. Tenía la cabeza borracha. Se abrió el cielo y cayó un rayo. [Los espíritus] me bajaron mi kultrung [tambor]. Después miré para arriba y me bajaron todos los remedios. Me tomaron el brazo derecho y le dieron poder.Toqué mi kultrung y oré y ya el terremoto paró. Se salvó el mundo" (24 de marzo de 1992). Al poco tiempo, Francisca tuvo un sueño con asociaciones católicas: "Subí por un palo grande y grueso hasta el WenuMapu [cielo mapuche]. Al igual que en el día de San Pedro, el cielo se abrió. (...)Y me dieron trébol, porotos, maíz, papas, trigo, lentejas. (...) Y cuando bajaba, un viejito con un bigote largo dijo: 'Voy a darte suerte'” (24 de marzo de 1992).

El parentesco de Francisca con la machi Rosa, basado en el trueno, su narrativa acerca de haber salvado al mundo de la destrucción y su sueño con asociaciones católicas legitimaban sus rituales. Además de utilizar una variedad de hierbas medicinales, Francisca invocaba a los espíritus ancestrales para desafiar las desigualdades de poder, resistir a los agentes estatales y curar el sufrimiento. Pero también buscaba su provecho personal. Tomaba partido en los conflictos entre facciones en Millali y se decía que echaba maleficios sobre sus enemigos, incluyendo al longko (jefe de la comunidad). Algunos la veían como awingkada (como una wingka o no mapuche). Cuestionaban su legitimidad porque se había iniciado a edad avanzada y no había recibido ningún tipo de entrenamiento formal. Otros envidiaban la riqueza y el poder de Francisca y la llamaban "bruja" porque violaba las normas de género mapuche: ganaba dinero en forma independiente fuera de su hogar y no retribuía suficientes favores a la comunidad; se negó a volverse a casar cuando enviudó y algunos la consideraban masculina, agresiva y amoral (Bacigalupo 2010). Al igual que las mujeres mestizas peruanas del mercado (De la Cadena 2000: 25, 229), Francisca representaba la transgresión moral porque cuestionaba las normas de género patriarcal. Consciente de estas circunstancias, temía que su espíritu no renaciera en el cuerpo de una nueva machi luego de su muerte. Para asegurarse de que no se perdiera su espíritu, me pidió que escribiera su biografía en forma de "biblia".

\section{COLONIZACIÓNY MESTIZAJE EN LA CONFIGURACIÓN DEL PODER CHAMÁNICO}

Michael Taussig (1987) ha argumentado que el poder chamánico se produce y reproduce a través de procesos históricos complejos -incluyendo el proceso de mezcla cultural y social denominado "mestizaje"generados por el colonialismo, el capitalismo y la evangelización. Pero el poder chamánico mapuche también se produce y reproduce mediante historias encarnadas locales que reinterpretan procesos históricos más amplios a través de una óptica chamánica. En la actualidad, I.200.000 de personas se identifican como mapuche, lo que las constituye en una de las poblaciones indígenas más numerosas de Sudamérica. Desde al menos el siglo XVI, los Mapuche $y$ sus chamanes han estado yendo $y$ viniendo entre Chile y Argentina para aumentar sus riquezas y obtener trabajos estacionales, buscar cónyuges indígenas y no indígenas, curar pacientes y visitar parientes. Mantuvieron su soberanía hasta que fueron incorporados por los chilenos (I88I) y los argentinos (1879) y perdieron $9.500 .000 \mathrm{~s}$ de hectáreas de territorio (Bengoa 1999:61).

Chile no adhiere al mito del mestizaje, pero la cultura se construye racialmente y solía justificar las diferencias sociales y el racismo sistemático en contra de los Mapuche (Richards 2013: 8, 17). Los Mapuche a veces recurren a criterios esencialistas tales como el lenguaje, la genealogía o la sangre para 
clasificar a una persona, y a menudo agrupan a los Ingka, Quechua, peruanos, españoles y chilenos en la categoría de wingka, refiriéndose a los de afuera provenientes del norte. Como una champuria, con madre mapuche y padre wingka, Francisca tenía una identidad relacional. Era a la vez parte y contraparte de cada una de sus identidades. Pero los Mapuche también usan las identidades contextual y relacionalmente; la manera de utilizar estas categorías depende, por ejemplo, de cuánto tiempo estuvieron los otros viviendo y comiendo con ellos, y si los otros se comportan según las normas morales y sociales mapuche en contextos especiales (Bacigalupo 200I, 2003, 2005; Course 20II). ${ }^{3}$ Tal como ocurre con otros pueblos indígenas (Comaroff y Comaroff 1991:17, De la Cadena 2000: 222-223), las categorías de identidad mapuche que parecen fijas son en realidad un flujo constante.

Las machi complican las categorías étnicas aún más pues deben habitar múltiples identidades para mediar entre otros tiempos, mundos, géneros y seres a fin de curar y mantener el orden moral (Bacigalupo 200 I, 2004a, 2004b). Hasta principios del siglo $X X$, se pensaba que las machi de origen mestizo poseían poderes especiales que les permitían ver el mundo tanto como si fueran personas de adentro como de afuera. Los Mapuche de Millali avalaban a Rosa, la predecesora chamánica mestiza (mapuchealemana) de Francisca, como una verdadera machi porque equilibraba la diferencia de manera tal que curaba y promovía el bienestar colectivo. Rosa también vivía en la comunidad y se comportaba de acuerdo con las normas morales y sociales mapuche (ver Bacigalupo 2013). Machi Jorge, por el contrario, era racialmente mapuche pero se lo interpretaba como un brujo awingkado porque acumulaba riqueza y prestigio personal a través de creencias y prácticas modernas a expensas de la moralidad mapuche, las jerarquías sociopolíticas locales y los ideales igualitarios de la comunidad (Bacigalupo 2005).

Ya a comienzos del siglo $X X$, muchos Mapuche empezaron a comprender el parentesco a través de lazos de sangre como un hecho natural irrevocable, en tensión con el parentesco adquirido a través del compartir la esencia espiritual, el lenguaje, el comensalismo y las relaciones espirituales. ${ }^{4}$ El mapuche intelectual Juan Ñanculef explica que "el parentesco y la memoria social están en mollfüñ, la sangre, el ADN. Si la calidad de la raza es mala, tendremos una sociedad conflictiva" ( 10 de enero de 2006). La vigilancia de la raza en base a la sangre con frecuencia reflejaba diferencias étnicas y conflictos entre facciones dentro de las comunidades. Dado que los poderes espiritual, político y económico son parte del mismo ámbito histórico (Gordillo 2003:121), las prácticas de mestizaje fueron objeto de grandes sospechas cuando los Mapuche perdieron sus tierras y su soberanía en 1884. Las tierras mapuche fueron vendidas a colonos no mapuche y los Mapuche se vieron forzados a vivir en reducciones. Una de estas reducciones corresponde a Millali, la comunidad de Francisca ubicada a 13 $\mathrm{Km}$. de la ciudad de Temuco y a $5 \mathrm{Km}$. del pueblo de Quepe. Los Mapuche de Chile, despojados de su territorio, perdieron su poder al tener que trabajar como mano de obra para agricultores y compañías forestales o al verse obligados a emigrar a las ciudades. Este faccionalismo fue en aumento con la posterior asimilación y reducción territorial bajo la dictadura militar chilena (1973-1989). Los gobiernos democráticos que siguieron (1989-2013) usaron las tierras de los Mapuche para proyectos de modernización y buscaron incorporar a los indígenas a la economía global.

Debido a las percepciones mapuche de diferencia racial, la identidad champuria de Francisca y sus prácticas chamánicas fueron cuestionadas y eran contradictorias y tensas. Francisca intentó restaurar su legitimidad alegando que había heredado los poderes chamánicos de la prestigiosa machi Rosa Kurin, quien, según afirmaba, era su abuela materna. Además, se cambió el nombre por el de Francisca Kolipi Kurin. Los chamanes que participan de la "tradicionalización de la subjetividad chamánica" (Oakdale 2005: 79, I67) con el fin de obtener poderes regenerativos a menudo logran instaurar la autoridad activamente mediante la referencia a un pasado prestigioso (Bauman 2004:I50-152).Al alegar que ella era una "champuria como Rosa", Francisca se apropió de los poderes especiales de las machi mestizas del pasado. Al igual que Rosa, Francisca también se identificaba como mapuchada (como una Mapuche) porque era una machi analfabeta que no ganaba un salario sino que vivía en una comunidad rural, hablaba Mapudungun y sabía de hierbas medicinales, tradiciones y conocimiento ancestral.

En otros contextos, Francisca afirmaba ser una "machi civilizada" con un amplio conocimiento 
de los mundos mapuche y no mapuche. Sostenía que manejaba estratégicamente el Mapudungun y el español, la oralidad y la alfabetización, los conocimientos urbanos y rurales y el chamanismo, el catolicismo y la biomedicina para realizar un trabajo honorable (Bacigalupo 200I, 2003, 2005, 2016.). Sin embargo, muchos habitantes de Millali veían su participación en lo diferente como algo contrario a las normas morales y sociales mapuche, pues creían que ella estaba más interesada en su propio bienestar que en el bienestar colectivo.

Luego de la muerte de Francisca en 1996, su comunidad primero olvidó deliberadamente su controvertida individualidad champuria para dejar partir su espíritu. Más tarde, en 2009, cuando la comunidad empezó a prosperar, algunos comenzaron a recordarla bajo una luz positiva y a indigenizarla otra vez dentro de un contexto político e histórico nuevo. El espíritu de Francisca ahora podía ser individualizado nuevamente, podía adquirir una nueva forma textualizada en la "biblia" que yo escribiría sobre ella, y renacer. Esta "biblia" constituiría la nueva identidad indigenizada y los poderes chamánicos positivos de Francisca, en su rol de mediadora del colectivo mapuche.

\section{LA CREACIÓN DE LA “BIBLIA” DE FRANCISCA A TRAVÉS DE IDENTIDADES CHAMPURIAS Y LA ALFABETIZACIÓN GRÁFICA}

Las múltiples y mutables identidades de Francisca y la mía propia la llevaron a pensar que yo podía escribir un texto que la representara y pudiera mediar entre los órdenes mapuche y no mapuche. Francisca me describía como alguien similar a ella y a la vez diferente pues mi padre tiene parte de ascendencia quechua de Perú y porque yo pasé mucho tiempo con los Mapuche. Sin embargo, se negaba a reconocer que yo fuera peruana porque los Mapuche pelearon en contra de la expansión Inkade Perú a Chile (1483-85). En cambio, Francisca me identificaba como una champuria de la Patagonia argentina oriental, una zona vinculada con parientes y aliados mapuche. Mi primer encuentro con gente mapuche fue a la edad de cinco años, en el fundo de mis abuelos maternos situado en la Patagonia argentina, donde solía pasar los veranos. Muchos de estos Mapuche eran trabajadores de temporada del sur de Chile que conocían a Francisca. La propiedad estaba ubicada cerca del lugar de nacimiento de Rosa Kurin, de modo que Francisca ya había oído hablar de mi familia mucho antes de que nos conociéramos.

Francisca y yo éramos mujeres champurias muy diferentes:por mi lado, me diferenciaba de ella por mi educación y mi estatus económico, mientras que ella se diferenciaba de mí por su poder y conocimientos chamánicos. De todos modos, Francisca creía que mi conexión con el lugar de nacimiento de Rosa y mi rol como ayudante de ritual champuria y alfabetizada me permitirían escribir una "biblia" que encerraría su poder chamánico. Si bien analfabeta, Francisca comprendía el poder de la escritura y me dijo: "Necesito que tú escribas mis historias, para copiar mi poder" (25 de febrero de 1992).

Francisca empleaba la alfabetización gráfica -la capacidad de comprender, interpretar y analizar datos representados gráficamente - y veía el alfabeto como una tecnología que inscribía significados de una manera gráfica sobre un objeto físico. Creía que tanto ella como otros chamanes podían manipular estas inscripciones con fines espirituales. Al igual que los indígenas andinos, Francisca se centró en la fenomenología del objeto ritual que contenía la inscripción gráfica o, según las palabras de Joanne Rappaport y Tom Cummins(2012:192), en "cómo la inscripción hace presente lo ausente $y$, por lo tanto, precede y autoriza cualquier tipo de decodificación de la palabra". Veía mi escritura como algo que representaba tanto sus narraciones orales como los sucesos históricos de Millali; las palabras eran diseños con fuerza, separados parcialmente de su significado escrito. Estos diseños podían representar la materialidad de su cuerpo de la misma manera en que la cualidad física de los altares, reliquias y escrituras genera la presencia de lo divino. Francisca creía que podía usar su poder chamánico para determinar cómo y qué iba a escribir yo. Pensaba que, si yo aprendía su conocimiento chamánico y le permitía controlar mis sueños, entonces ella podría imbuir mi escritura con sunewen(poder o fuerza) chamánico.

Al hacerme escribir su biografía usando el alfabeto romano, Francisca creía, además, que podría apropiarse del poder no mapuche, del wingka newen, contenido en la forma de la palabra escrita. $Y$ era esta interdependencia entre la alfabetización literaria, la alfabetización gráfica y la memoria oral 
y performativa indígena las que determinaron la creación de la "biblia" de Francisca como un objeto intertextual.

En vida de Francisca, reuní material sobre su persona y sobre otros Mapuche de Millali y zonas vecinas a fin de escribir su "biblia". De 199I a 1996 llevé un registro de lo que Francisca me contaba sobre su vida, su familia, su relación con la comunidad y sus poderes y prácticas rituales. Yo participaba de su vida cotidiana y oficiaba de ayudante del ritual. Entre 1991 y 2013 otros Mapuche dentro y fuera de su comunidad me hablaron sobre el rol de las biografías chamánicas en la construcción de la historia mapuche. A partir de la muerte de Francisca, realicé una investigación etnográfica sobre la memoria colectiva de la comunidad y las percepciones de sus miembros sobre mi investigación y el uso que le darían a lo largo del tiempo (1997-20I3). Asimismo, llevé a cabo investigación de archivo en las ciudades de Santiago y Temuco (2007-20I3).

Francisca quería que yo escribiera un texto que fuera leído por Mapuche y no Mapuche alfabetizados. Al morir en 1996, el 90 por ciento de la población indígena de Chile sabía leer y escribir en español. En la actualidad, este porcentaje aumentó al 95 por ciento (Gobierno de Chile 20l I). Si bien mi intención era escribir la "biblia" de Francisca, tal como la imaginaba, su voz estaba representada indirectamente a través de mi propia identidad, de la dinámica de poder del trabajo de campo y de los requerimientos de la escritura académica. En algunas ocasiones, Francisca pretendía controlar el contenido y me decía: "Trae el grabador que tengo algo importante para decir", o más directamente:"Escríbelo en el libro" (2I de noviembre de 1991). En otros momentos, se quejaba de que yo le hacía "preguntas estúpidas", cuyas respuestas eran necesarias para contextualizar sus palabras ante un público no mapuche. En el trabajo de campo, Francisca era una machi poderosa que determinaba qué rol debía desempeñar yo en sus rituales y en la vida cotidiana y qué debía grabar. Pero yo tenía el poder de representarla en mi escritura. Francisca estaba bien al tanto de la dinámica de poder de la escritura y me pidió que escribiera su "biblia" en español e inglés. La versión inglesa legitimaría su vida y práctica para la comunidad textual internacional, cuyas percepciones tenían más peso que las del Estado chileno dentro de la economía global de poder. La versión española narraría su historia en la comunidad y serviría a las temporalidades chamánicas al hacer circular su fuerza chamánica para lograr su renacimiento.

La"biblia" de Francisca incluye sus narraciones sobre su vida y práctica, así como mi análisis de sus diferentes modos de performatividad chamánica: multitemporalidad, remodelado ritual del pasado y el futuro, recreación de la historia local a través de la chamanización de documentos oficiales y de biblias, obliteración espiritual de la historia nacional chilena y transformación de la memoria a través de la muerte y el renacimiento. Asimismo, narro cómo los habitantes de Millali y los descendientes de colonos alemanes utilizan la dislocación temporal para construir historias de relaciones intra e interétnicas.

No obstante, a fin de entender cómo Francisca y su familia planeaban usar mi "biblia" para crear historia local debemos comprender el rol de la biografía y el poder chamánicos en la producción de la historia mapuche.

\section{BIOGRAFÍA CHAMÁNICA, HISTORIAY CONCIENCIA HISTÓRICA}

Las biografías chamánicas orales son fundamentales para la construcción de la historia mapuche rural dado que son testimonios de los procesos históricos en sí: continuidad, cambio, muerte y renacimiento. Al narrar historias sobre machi del pasado, los chamanes vivos convocan a los espíritus de las machi fallecidas. Walter Benjamin (I982) visualiza "al ángel de la historia occidental" mirando las ruinas del pasado; sin embargo, es incapaz de reconstruir estas ruinas o revivir a los muertos porque el ángel es impulsado irresistiblemente de espaldas hacia el futuro. Los Mapuche también enfrentan el pasado pero su pasado no está en ruinas. Tampoco los difuntos están ausentes. La idea de Paul Connerton (1989: 72) sobre la primacía del hábito corporal y ritual en la construcción de la memoria nos ayuda a comprender cómo la memoria corporal de los Mapuche recrea las experiencias indígenas de la historia. En sus rituales, Francisca encarnaba los espíritus del pasado mediante gestos, hábitos, movimientos, expresiones faciales y sonidos a fin de hablar del presente y del futuro. Del mismo modo, su "biblia" en el futuro convocaría a su espíritu. Por otro lado, les haría comprender a los miembros de la comunidad su posición y la de Francisca dentro de 
procesos históricos más amplios, así como dentro del ciclo cosmológico de vida, muerte y renacimiento.

Las biografías chamánicas orales también expresan los cambios ideológicos ocurridos en la comunidad e ilustran cómo se van modificando las percepciones mapuche sobre la condición de persona en distintos momentos. Las biografías orales narran las complejas relaciones de las machi con un sinfín de personas de distintas épocas: santos cristianos, conquistadores españoles, colonos alemanes y antropólogos, además de animales, espíritus y seres de la naturaleza (ver Basso 1989; Oakdale 2005). La historia mapuche reúne las experiencias personales de los chamanes, reconoce la encarnación periódica de los espíritus de chamanes pasados en nuevas machi e identifica los espíritus chamánicos ya sea como identidades individuales o colectivas. Los nombres y las identidades de chamanes (como Rosa y Francisca) y jefes prominentes se diluyen en los de personajes difuntos o míticos para la creación de historias regionales (Bacigalupo 2010).

Los Mapuche rurales hacen uso de narrativas biográficas chamánicas para desafiar la historia chilena convencional -la historia de su subordinación al Estado- y presentarse como los triunfadores espirituales de esa historia. Expresan su pasado en términos de la comprensión histórica chamánica, a través de narrativas que fusionan las piam (historias cíclicas de creación, transformación y destrucción) con las nütram (narrativas cronológicas lineales del pasado reciente; ver Bacigalupo 20I3). En resumen, las biografías chamánicas mitifican a las machi a la vez que rehistorizan y politizan mitos en contextos nuevos. Los Mapuche utilizan estas narrativas para transmitir la capacidad histórica de accionar de los indígenas, un uso que está arraigado en las capacidades transformadoras del poder espiritual. Francisca empleaba esta capacidad transformadora para leer diseños gráficos y el alfabeto a través de su óptica chamánica.

\section{EL GRAFISMO INDÍGENAY LAS \\ ALFABETIZACIONES CHAMÁNICAS: LAS POLITIICAS DE LECTURAY ESCRITURA}

En su artículo “Lección de escritura”, Claude Lévi-Strauss (1955: 350, 352-355) hace uso de una limitada comprensión de la escritura para argumentar que los pueblos indígenas tienen culturas orales que son oprimidas y alienadas por sistemas de inscripción europeos. El explorador decimonónico Edmund Reul Smith (I855: 22I-222) consideraba que el alfabeto era el único parámetro de civilización y discriminaba a los Mapuche por no poseer uno. Pero incluso antes de la llegada de los conquistadores españoles en el siglo XVI, los pueblos indígenas escribían utilizando sus propios sistemas de inscripción y comunicación visual en los que, a diferencia del sistema alfabético, los signos representaban referentes más que sonidos (Salomon y Niño-Murcia 20I I; Santos Granero 1998). Los Mapuche creaban diseños gráficos en textiles e inscripciones glíficas en joyas de plata que siguen siendo "leídos" por las generaciones de mayor edad y por chamanes como Francisca. Estos diseños e inscripciones son "imágenes metadiscursivas de una cultura aparentemente duradera y con posibilidades de ser compartida y transmitida" (Silverstein y Urban 1996: 2). Describen historias míticas y familiares, rituales y formas de organización social y política.

Durante el proceso de colonización, los Mapuche y muchos otros pueblos indígenas conectaron sus propios sistemas gráficos y formas de representación con el alfabeto europeo (Gow 1990; Hugh-Jones 2010; Perrin 1986; Platt 1992). Poco a poco, fueron incorporando la escritura de documentos legales al grafismo indígena (Salomon y Niño-Murcia 20l I), un proceso social que incluye interacciones con la oralidad, los actos rituales, la experiencia corporal y las formas pictóricas y alfabéticas. Francisca consideraba que los grabados pintados sobre su rewe, su árbol de la vida o eje del mundo, eran semejantes a palabras escritas, y veía la escritura alfabética como diseños con fuerza que actuaban pero no hablaban. Estaba interesada en la calidad gráfica de la escritura —el tamaño y la distribución de las palabras en una página- y no en las palabras como representaciones visuales del habla (cf. Gow 1990: 92).

Sin duda, la interpretación textual mapuche presupone una base multimedia. El término mapuche chillka (derivado del vocablo quechua quilca) se refiere al material sobre el que se realiza una inscripción (piedra, madera, vegetal, papel). Pero el término también puede aludir a letras, inscripciones y diseños, y a leer, descifrar, interpretar y aprender (Cárcamo-Huechante 201 I: I46; Gerbhart-Sayer 1985; Gow 1990). El término escritura se traduce por lo general como wirin, vocablo 
referido a algo que se inscribió o dibujó y que también denota líneas, signos, diseños y bosquejos (Erize 1960: 206); y la escritura produce textos, aunque no todos los textos poseen el mismo valor o poder. Francisca hacía una distinción entre chillkanewen (textos con poder) y chillkala (textos muertos), que no son ni documentos oficiales ni biblias. Francisca comentó que, si ella tratara de leer libros escolares, periódicos o cartas personales, su mundo espiritual "la achacaría con kastikukutran [enfermedades de castigo] porque aprender leyendo 'textos muertos' rompe la fuerza de la machi" (I 0 de enero de 1992; ver Gill 1985:233,226, 228 para modos activos e inactivos de comunicación).

Francisca practicaba lo que denomino "alfabetización chamánica": leía textos utilizando prácticas de alfabetización gráfica y también los usaba como objetos rituales.Al igual que otras machi, Francisca se interesaba por las palabras de chillkanewen, tanto sagradas (biblias cristianas, "biblias" místicas mapuche y etnografías de machi) como oficiales (títulos de propiedad de tierra y otros documentos legales). Las machi y sus seguidores consideran que los poderes de la Iglesia y el Estado que emergen de estos textos son análogos a los poderes propios de una machi. Francisca veía las palabras de estos documentos como formas animadas "que bailaban por toda la página”, de las cuales ella podía extraer newen. Al igual que los sanadores songhai de Níger (Stoller 1980: 129), ella conceptualizaba las "palabras poderosas" como energía o entidades vivas con una existencia separada de los ámbitos de la vida humana, animal y vegetal. Francisca clasificaba todas las biblias cristianas como chillkanewen, pero hacía una distinción entre la biblia luterana, que contenía las palabras del demonio, las biblias católicas y anglicanas, que contenían las palabras de Dios, y la "biblia" que yo iba a escribir para acumular y hacer circular su poder chamánico después de su muerte.

Al utilizar así estos textos poderosos como objetos rituales, las machi como Francisca evocan una alfabetización chamánica gráfica y performativa, además de una temporalidad chamánica que prima sobre los supuestos epistemológicos seculares y racionales que subyacen la historiografía académica positivista. Cuando en 1996 le entregué a Francisca una copia de mi monografía Adaptación de los métodos de curación tradicionales mapuche:la práctica de la machi contemporánea en Chile, ella fumó encima de mis citas de rogativas chamánicas - “letras chicas poderosas como en la Biblia", las denominó-, con el objeto de revivirlas. "Ese es el newen de Ngünechen [la deidad mapuche], de Jesús, todo.Las letras chicas son la machi, la palabra, el conocimiento. Yo lo fumo y mis huesos se fortalecen. Nadie me lo puede ganar. (...) En el libro tú pondrás letras chicas. Palabra con newen" (I5 de julio de 1996). Francisca quería que yo canalizara su poder espiritual a través de mi escritura, de la misma manera en que ella canalizaba los espíritus. $\mathrm{Si}$ las machi leen un texto, le confieren autoridad a ese texto. Si experimentan el texto y le fuman encima, reviven el alma del texto y subordinan los supuestos de las epistemologías de la historiografía positivista a los espíritus, cuyo "poder fluye a través de los textos y cuyas palabras son fuerza en acción" (Goldman 201 I: 424-425). Los textos que contienen poder chamánico facilitan la comunicación entre vivos y difuntos y el presente, pasado y futuro. Tal como argumenta Dipesh Chakrabarty (2000: 238-239), una conciencia histórica racional limita la relación vivida entre el sujeto observador y otros tiempos etnográficos o históricos, mientras que las machi buscan mantener una relación viva con el pasado.

La "biblia" de Francisca podría leerse a través de alfabetizaciones tanto chamánicas como comunes y corrientes: sería portadora de sus poderes chamánicos y los extendería al futuro, aunque también podría ser leída por Mapuche y no Mapuche alfabetizados, cosa que les permitiría recordarla después de su muerte. El doble significado que Francisca asignaba a los textos está relacionado con el poder inherente a los documentos oficiales.

\section{EL PODER DE LOS DOCUMENTOS OFICIALES}

En la actualidad, los Mapuche consideran que los documentos oficiales son tanto instrumentos de colonización vinculados al poder político y legal del Estado nación chileno como textos poderosos que ellos pueden desafiar, imitar y manipular espiritual y políticamente. Ellos piensan que los colonizadores crearon leyes implementadas por documentos oficiales, tales como títulos de propiedad de tierra, para facilitar el proyecto estatal de modernización permanente y para realzar su acción colonizadora a fin de controlar y "civilizar" al pueblo mapuche (Mallon 2009). La Ley de Radicación de Indígenas fue redactada en 1866 para hacer un relevamiento de los territorios indígenas que se estaban incorporando 
al Estado chileno. Esta ley técnicamente protegía las tierras mapuche de ser usurpadas al impedir la subdivisión y venta formales, aunque en la práctica no lo hizo. En 1885, mucho antes de que los habitantes de Millali se hubieran constituido como comunidad indígena y recibieran sus títulos de propiedad de tierra (cosa que recién ocurrió en 1909), el gobierno chileno subastó el noventa por ciento de sus tierras a colonos. En 1927, el gobierno chileno promulgó una ley de privatización, lo que llevó a que las tierras de las reducciones indígenas se dividieran en propiedades privadas y fueran vendidas a personas no mapuche o fueran eliminadas de los registros escritos (ver Bengoa 1999: 59). En 1979, el dictador Augusto Pinochet promulgó otra ley que abolía el carácter comunal de las reducciones. Así, muchos Mapuche que habían arrendado sus tierras a personas no mapuche por 99 años jamás las recuperaron.

Los Mapuche reaccionaron a las acciones colonizadoras del gobierno resistiendo los discursos arraigados en los documentos oficiales del Estado. Algunos Mapuche eludieron entrar en contacto con censistas y topógrafos y adoptaron la invisibilidad en el registro escrito como una estrategia defensiva en contra de discriminaciones, persecuciones, la conscripción y otras amenazas a su autonomía. Otros deliberadamente trastocaron los archivos dando nombres falsos a los censistas, agregando u omitiendo miembros de la familia para obtener beneficios o clasificando los escritos no mapuche como brujería (Bacigalupo 2016).

No obstante, la escritura alfabética les permitió a los Mapuche representar y compartir su cultura aparentemente duradera de un modo reconocible para los europeos. La escritura se convirtió en una fuente de legitimidad para los indígenas al conferirles poder cultural y político y permitirles utilizar textos oficiales de manera antagónica. Mientras que la escritura puede transformar las formas indígenas de la memoria, los títulos de propiedad también pueden vincular a los pueblos indígenas con acontecimientos, lugares y derechos de origen mitohistóricos de un modo irrevocable (Rappaport 1998). Hacia el siglo XIX, los Mapuche escribían sobre todo en español pero también en su propia lengua, Mapudungun, para subvertir los discursos arraigados en los textos oficiales del Estado y para crear archivos mapuche autónomos (Menard 20I0; El Meteoro de los Ángeles
1869; Pavez 2008). Hubo Mapuche alfabetizados que crearon sus propias estampillas, cartas y periódicos para divulgar la correspondencia política de líderes guerreros no conquistados (Pavez 2008). Por otro lado, produjeron historias familiares, historias nacionales étnicas (Cárcamo-Huechante et al., 20I2; Mariman et al., 2006) y "biblias" místicas mapuche (Menard 2010).

Los documentos oficiales no sólo "dejan filtrar la magia del Estado en manos de las personas que dominan" (Taussig 1987: 264) sino que los Mapuche creen que pueden apropiarse del poder de esos documentos y transformar su significado. En 1996, Francisca trató de revivir el mapa del título de propiedad de Millali de 1909 para traer al presente las realidades bajo las que se había constituido el mapa y, así, recuperar las tierras que habían sido usurpadas. Fumó encima del mapa mientras cantaba "Así como es en el cielo, así es en la tierra de abajo" [Chumleita wenumapu kafelitanangmapu] (2 de febrero de 1996). En 2008, la comunidad presentó un reclamo territorial escrito ante la Corporación Nacional de Desarrollo Indígena (CONADI), donde se denunciaba a propietarios no mapuche por usurpación de tierras y se solicitaba la restitución de las 51 hectáreas que habían perdido desde 1909. En diciembre de 2009, la CONADI devolvió las 51 hectáreas, que ahora representan el 20 por ciento de las tierras de Millali.

El reclamo escrito de la comunidad era un documento legal de petición al Estado y una forma de contrabrujería contra el Estado: una estrategia para cambiar la historia que hacía uso del poder de los textos oficiales en beneficio de la comunidad (ver Bacigalupo 2016). Francisca creía que sus cantos y el hecho de fumar encima del documento también tenían el poder de cambiar la historia; que al revivir el pasado colectivo en el presente, ella era capaz de recuperar la tierra de la comunidad y ofrecerles a sus miembros un futuro mejor mucho tiempo después de su muerte. Ella creía que, luego de su muerte, su espíritu machi perdería su individualidad y se mitificaría al fusionarse con el filew, el espíritu genérico de todas las machi. Pero si su espíritu habría de renacer en el cuerpo de una nueva machi, los habitantes de Millali y la nueva iniciada tendrían que recordar, en última instancia, alguna de las cualidades individuales de Francisca. Cuando me pidió que registrara su pasado y presente individuales escribiendo una "biblia" sobre 
su persona, esperaba rehistorizar y repolitizar su espíritu que habría de retornar.

\section{LA PRODUCCIÓN DE "BIBLIAS” MAPUCHEY LAS MACHI BÍBLICAS}

Se ha prestado muy poca atención al hecho de cómo los pueblos indígenas producen textos sagrados y los utilizan para hacer declaraciones políticas y narrar la Historia. Los estudiosos han demostrado que la producción de documentos legales indígenas garantiza legitimidad a los pueblos indígenas y reconfigura la memoria indígena de manera significativa (Rappaport y Cummins 2012; Salomon y Niño-Murcia 20 I I), y que todos los textos producidos por los Mapuche tienen el objetivo político de reivindicar los reclamos colectivos de identidad y otorgarles mayor legitimidad. Sin embargo, las "biblias" mapuche expresan una conciencia histórica alterna y su producción sigue una clara genealogía.

En el Chile decimonónico, al igual que en África, la Biblia —un texto sagrado no indígenase convirtió en la metonimia del poder colonial y en un instrumento de autoridad religiosa cristiana (Engelke 2003: 30I). Los Mapuche se apropiaron de las biblias católicas de los capuchinos y de las biblias protestantes de los anglicanos pero rechazaron las biblias luteranas alemanas pues estas confesiones desempeñaron roles totalmente diferentes en el proceso de colonización, evangelización y usurpación de tierras mapuche. Los luteranos alemanes no hacían proselitismo ni trataron de relacionarse con los Mapuche ni incorporar a los indígenas y sus creencias a su mundo, como sí lo hicieron los católicos y anglicanos.Así, las biblias luteranas estaban relacionadas con la usurpación y la explotación de la tierra mapuche por parte de ricos propietarios alemanes, y con el proyecto alemán de "civilizar" a los Mapuche haciéndolos trabajar como jornaleros. Los Mapuche creen que el demonio escribió la biblia luterana para imbuir el texto sagrado con sus poderes a fin de que los alemanes pudieran destruir la moralidad y sociabilidad mapuche (Bacigalupo 2016).

Por el contrario, los Mapuche interactuaron con las biblias de los capuchinos y anglicanos, que asociaban con el poder de Dios, la evangelización y la alfabetización. Estas biblias inspiraron la producción de "biblias" mapuche y tuvieron un uso chamánico como objetos rituales. Los Mapuche de la zona de Quepe recibieron una fuerte influencia de las lecturas bíblicas por parte de misioneros capuchinos católicos italianos y protestantes anglicanos estadounidenses durante el siglo XIX. El objetivo de los capuchinos era evangelizar a los Mapuche e incorporarlos por completo al Estado chileno y a la Iglesia Católica. Con este fin, crearon paralelos entre las figuras, creencias y prácticas divinas católicas y las de los Mapuche. Los capuchinos ganaron adeptos expulsando demonios $y$, en estas acciones, tanto las machi como los sacerdotes encontraron paralelos en sus identidades y prácticas rituales (Bacigalupo 1995, 2007, 2008). Los misioneros anglicanos eran aún más abiertos a la cultura mapuche que los capuchinos y permitían la continuidad de la poligamia y del juego del palín entre los Mapuche. Pero los maestros y misioneros anglicanos en Quepe también alfabetizaron y enseñaron la integración con el Estado y la Biblia ya en 1895 (Menard y Pavez 2007).

Los Mapuche valoraban las biblias anglicanas y capuchinas como una manera de acceder al poder curativo de sus autores, santos y deidad, y como un modo nuevo de expresar el poder místico y de registrar la memoria histórica. Muchos líderes y místicos mapuche educados en la misión de Quepe utilizaron la Biblia de maneras novedosas que confirieron sentido a sus identidades sin integrarlos necesariamente a la homogénea sociedad nacional chilena (Menard y Pavez 2007). Estos líderes eran conscientes del poder simbólico de la producción escrita y se la apropiaron para incrementar su propio estatus y desarrollar formas escritas "civilizadas" mapuche de conciencia mística y político-histórica similares a las de las machi. Por otro lado, estos líderes y místicos mapuche trastocaron el discurso de los misioneros católicos capuchinos y protestantes anglicanos argumentando que Dios habla en forma directa con los chamanes mapuche, lo que hace innecesarios a los sacerdotes y ministros (Delrío 2005:108-109).

A principios del siglo $X X$, los místicos mapuche empezaron a involucrarse de maneras nuevas con la Iglesia a través de la producción de sus propias "biblias". Situaron el sistema simbólico cristiano europeo dentro del contexto espiritual y sociopolítico mapuche. Los místicos alfabetizados manipulaban la oralidad y alfabetización según 
múltiples criterios culturales a fin de negociar la forma en que sus visiones del mundo impactarían en la sociedad postcolonial chilena. Pusieron por escrito narrativas anteriormente orales referidas a sueños y encuentros con santos y espíritus de un modo que combinaba el tiempo mítico con el lineal. Escribieron "biblias" para incorporar el poder de Jesús y de sus apóstoles a las epistemologías chamánicas y legitimar las concepciones chamánicas de la historia (Crow 2010: 135, I37, I43; Foerster 1983: I 15; Mallon 2005: 90; Menard y Pavez 2005: 5I; ver Menard 2003). El místico Aburto Panguilef, por ejemplo, fue "poseído por la escritura" —produciendo cientos de páginas en las que describió sus sueños y reflexiones sobre la práctica espiritual y política- y veía su texto como un objeto potente (Menard 2003, 20I0). Panguilef era un místico no un chamán pero creó paralelos entre los roles de los sacerdotes católicos, de los chamanes y de los místicos.

Panguilef intentó crear una identidad étnica y política mapuche separada, en base a la performatividad de rituales, sueños y normas sociales tradicionales. Defendía la continuidad de la poligamia, de los machitun o datun (rituales de curación chamánica) y de los ngillatun (rituales de fertilidad colectivos), al tiempo que involucraba a intelectuales progresistas (Foerster 1983: II5). Panguilef celebraba la "brillante historia" de la resistencia mapuche a la asimilación por parte del Estado chileno, argumentando que las tierras ancestrales eran un espacio para la cultura tradicional, la práctica espiritual y la memoria histórica (Crow 2010: I35, I37, I43; Mallon 2005: 90; Menard y Pavez 2005: 5 I). Incorporó el cristianismo a su práctica y le rogaba al Dios de todos los santos que bendijera a los Mapuche, "el pueblo elegido", afirmando su relación única con la divinidad y la naturaleza (Crow 2010: I37; Menard 2010). Al mismo tiempo, recurría al misticismo judío y al concepto cristiano de "justicia divina” más que a la historicidad chamánica mapuche.

Severiano Alcaman, un Mapuche educado por los capuchinos en la segunda mitad del siglo $\mathrm{XX}$ que luego se convirtió en sacerdote y antropólogo, escribió una "biblia" en la que buscó registrar el poder chamánico y los rituales mapuche y legitimarlos como enseñanzas divinas semejantes a las de Jesús. Utilizó su posición de prestigio para legitimar los poderes chamánicos y las creencias mapuche a los ojos de la mayoría chilena.
Para algunos Mapuche, la lectura e interpretación de las biblias cristianas compite con la capacidad de accionar de los chamanes y con su experiencia directa con espíritus a través de la oración y la posesión, y las socava. El Longko Jorge Sandoval argumentaba que "las machi que usan textos y biblias no son espirituales. Las machi deben seguir a sus espíritus y no tener la biblia delante de ellas [guiándolas]" (4 de enero de 20I I). Pero cuando las machi utilizan biblias como objetos rituales más que como agentes en pugna, los textos se convierten en instrumentos cruciales de la práctica chamánica y de las biografías machi.

Las "biblias celestiales" figuran de un modo prominente en las narrativas de sueños de las machi y compiten con las "biblias celestiales" veneradas por Mapuche evangélicos. Los Mapuche evangélicos dicen que los nombres de los que serán salvos están escritos en letras doradas en una "biblia celestial" (Foerster 1996). Las machi, en cambio, vinculan las "biblias celestiales" con sus propias historias de vida. Así, en el sueño iniciático de machi Marcelina, la Virgen María tenía "en la mano un papel que parecía un testamento... y encima de su cartera una biblia enorme con el nombre [de Marcelina] escrito en su interior y una cruz de plata" (Bacigalupo 2004a: 442). Machi José supo en su sueño que mis escritos etnográficos sobre su persona se reflejarían en su "biblia celestial": "Si haces bien tu trabajo, Mariella, quedará escrito en el cielo. (...) Será como una 'biblia' sobre mi'” (Bacigalupo 2007: I42). Pero machi Francisca no soñó con una "biblia celestial". Quería que, luego de su muerte, yo escribiera una "biblia" sobre ella en esta tierra, pues creía que, a través de esa "biblia", regresaría su espíritu chamánico.

De esa manera, Francisca daba nueva forma al mundo de la oralidad, del poder chamánico y de los espíritus mediante su uso de la biblia católica y así reconstruía la historia. ${ }^{5}$ Exhibía una copia de la biblia en la sala de su casa como un objeto material de poder del cual ella podía apropiarse chamánicamente para utilizar la palabra de Dios en beneficio de sus pacientes. Oraba y fumaba encima de su biblia católica para "revivir" las palabras de Dios y colocaba hojas de los árboles sagrados foye y triwe en su interior para "activar" sus propiedades medicinales antes de preparar los tratamientos herbarios. A continuación, frotaba la biblia católica sobre los cuerpos de sus pacientes durante la curación y luego la cerraba de 
un golpe cuando lograba atrapar un espíritu maléfico wekufüen en sus páginas.

La "biblia" de Francisca era un poderoso objeto animado y sagrado y no un fetiche mercantilizado. Un dios, un espíritu o un alma reside en objetos animados y les "da vida". Los objetos fetiche, sin embargo, actúan y emiten mensajes y significados por cuenta propia en virtud de sus extraordinarias propiedades materiales (Pels 1998: 94-95). El poder de los objeto fetiche está determinado por valores y deseos abstractos que no guardan relación con el trabajo invertido en fabricar el objeto o con su función utilitaria (Marx 1977: 164-165). Los chamanes coreanos, por ejemplo, valoran las pinturas de dioses como objetos animados que transmiten energía espiritual; sin embargo, el mercado del arte valora estas mismas pinturas como antiguos fetiches mercantilizados que pueden venderse (Kendall y Yang s. f.). La "biblia" de Francisca era un objeto animado que absorbía su poder de machi, tal como (según ella creía) la biblia católica absorbía los poderes de Dios, Jesús y los apóstoles. Francisca afirmaba su superioridad sobre otros Mapuche alegando que ella era el sujeto de mi "biblia" y que la materialización de sus palabras en el texto inmortalizaría su poder.

Taussig (1993) y Paul Stoller (1995) argumentan que las personas menos poderosas pueden copiar a sus dominadores en un intento por convertirse en ellos y apropiarse de su poder extraordinario. Pero como señala Fernando Santos Granero (2009: 488, 492, 493), esta estrategia creativa puede también constituir un intento de los menos poderosos por dominar al Otro hegemónico utilizando las herramientas culturales disponibles. Panguilef,Alcaman, Francisca y otras machi intentaron apropiarse de los poderes de los dominadores a través de versiones de biblias capuchinas y anglicanas amerindianizadas y mágicamente alteradas y producidas. Al hacer esto, interpretaban sus identidades étnicas y personales y su autonomía política en un contexto nuevo. Los hombres mapuche se identificaban como "machi católicos", "sacerdotes machi", "sacerdotes espirituales" o "machi bíblicos" (ver Bacigalupo 2005), pero no querían pasar a ser como los wingka cristianos en forma permanente. Empleaban conceptos y símbolos cristianos indigenizados para "arrebatar el control del cristianismo de manos de los blancos, al tiempo que los remodelaban para satisfacer las necesidades del pueblo indígena" (Brown 1991: 401) y para producir sus propias "biblias". Francisca se identificaba como machi católica y se refería a su biografía como una "biblia" porque quería contribuir al desarrollo local de una conciencia mística mapuche que confiriera sentido a las identidades múltiples y mutables, tal como otros habían hecho bajo influencia de los misioneros cristianos.

Francisca me pidió que escribiera una "biblia" sobre ella porque quería que sus palabras tuvieran el peso del texto autoritario de la Iglesia y el poder de una "biblia" mística mapuche. Ella creía que mi biografía chamánica sobre su persona la validaría como una mística poderosa y una machi católica casi de la misma forma en que la Biblia cristiana validaba a Jesús y al poder de los wingka cristianos. Además, Francisca quería que su "biblia" acumulara e hiciera circular su poder chamánico después de su muerte. "Cuando muera, mis palabras quedarán en el libro”, decía (25 de febrero de 1992). Mientras que lo hablado, los rituales, las oraciones y las vidas de las personas son efímeros, las palabras impresas en una página son más permanentes. El espíritu, el temperamento, las habilidades y las prácticas encarnadas de Francisca podrían finalmente renacer en el cuerpo de una nueva machi, pero ella creía que su espíritu y su historia de vida individual se perderían a menos que fueran capturados en mi biografía.

Las relaciones de los Mapuche con esta multiplicidad de biblias - las usadas por distintas confesiones, las producidas por los místicos mapuche, las "biblias celestiales" de las machi y la "biblia" que estoy escribiendo sobre Francisca- tienen implicancias para la memoria personal y colectiva mapuche, para la conformación de la identidad y para las percepciones de lo sagrado. Los místicos escriben "biblias" para inscribir su interpretación de la memoria colectiva mapuche en forma de texto y para negociar las espiritualidades tradicionales y las nuevas identidades mestizas en relación con el Estado nación chileno y la Iglesia aunque en forma separada de estos. Las machi incorporan biblias a sus prácticas chamánicas y estos textos se convierten en objetos sagrados que acumulan y hacen circular el poder personal de un espíritu machi. Las biblias también pueden servir a fines colectivos y ser utilizadas para curar (biblias anglicanas, capuchinas y mapuche) o para destruir al otro (biblias luteranas). Al apropiarse de los poderes de los dominadores y emplearlos para 
sus propios fines, las machi cuestionan el proceso de colonización y evangelización y crean memorias colectivas nuevas en las que los Mapuche se convierten en vencedores espirituales de la historia.

Las biblias, por otro lado, modifican la forma de lo sagrado mapuche. Los poderes, la historia de vida individual y los sueños de Francisca quedarían representados indirectamente por mi "biblia" $y$ guardados permanentemente en un texto alfabético. Por otro lado, esta "biblia" desafiaría las percepciones chamánicas mapuche respecto de la construcción de la historia pues sería independiente de las cambiantes políticas de recordar y olvidar que tienen lugar en las comunidades mapuche.

\section{LA MUERTEY EL OLVIDO; EL RENACIMIENTOY EL RECUERDO}

El II de septiembre de 1996 Francisca decidió morir. Sus hijas, Bernardita y Aurora, lloraban mientras le quitaban las joyas. Cada una se quedó con algo. Bernardita decidió que yo debería conservar el anillo de Francisca y su tocado de cintas coloridas para la próxima machi, en caso de que su espíritu renaciera. Como académica peruana viviendo en los Estados Unidos, donde las estaciones son opuestas a las de Chile, yo era una de afuera y, por lo tanto, más cercana al mundo de los muertos. Bernardita razonó que yo podía conservar esos objetos para el futuro sin correr el riesgo de convocar al espíritu de Francisca de regreso. Como ayudante del ritual champuria de Francisca, yo era además una persona de adentro que sabía cómo cuidar sus objetos y cuándo sería el momento de devolverlos. Para los Mapuche, el recuerdo y el olvido van más allá de la vida y la muerte de la persona de una machi. Estas experiencias están moldeadas por las realidades sociales dinámicas de los vivos y por la cambiante condición de persona de los muertos. En el ciclo de recordar y olvidar, los espíritus mapuche desempeñan una función central como agentes de la historia.

La comunidad de Millali intencionalmente borró los recuerdos que tenía de Francisca y terminó con ella como persona para permitir que su espíritu se fusione con el espíritu genérico de todas las machi, el filew. ${ }^{6}$ Cortaron su tambor chamánico, cambiaron de lugar su cabaña y se negaron a pronunciar su nombre a fin de que su espíritu no retornara. Arrancaron el viejo rewe de Francisca, su árbol de vida chamánico, y lo tiraron en un arroyo cercano para que se pudra. Su familia me pidió que no escribiera su "biblia" en ese momento porque eso convocaría a su espíritu de regreso. La gente de Millali era especialmente cautelosa con el espíritu de Francisca porque su historia de vida reflejaba realidades incómodas de faccionalismo y acusaciones de brujería dentro de la comunidad (ver Bacigalupo 2010).

Hacia 2004, algunos de los conflictos entre facciones que habían agitado a Millali en vida de Francisca se habían aquietado. Uno de los nietos de Francisca se había casado con la nieta de un enemigo de Francisca, lo que generó la unión de facciones anteriormente enemistadas y la prosperidad de la comunidad gracias a la implementación de programas de desarrollo del gobierno. En 2009, el regreso de Francisca parecía inminente cuando el árbol külon que habían plantado sobre su tumba duplicó su tamaño. $Y$ en diciembre de ese año, la CONADI devolvió las $5 \mathrm{I}$ hectáreas de tierra a Millali. Junto con estos cambios, algunas personas de Millali reinventaron la memoria de Francisca de un modo que promovió la continuidad histórica entre el pasado y el presente, entre vivos y difuntos. En 2010, varios habitantes de Millali recordaron nuevamente a Francisca bajo una luz positiva y fusionaron su identidad con la de Rosa, su predecesora chamánica: "La machi acá era poderosa. Le caían rayos alrededor de la cabeza. Al principio decían que era una bruja. Pero después salvó a la comunidad. Cuando la tierra tembló, la machi oró y dejó de temblar. Vivió cientos de años y era muy, muy vieja" (4 de enero de 2010).

Esta nueva narrativa condensa los recuerdos de diferentes personas y acontecimientos diversos. Sintetiza las experiencias mapuche de continuidad cíclica y de capacidad espiritual de accionar y hace hincapié en la diferencia cultural y la identidad grupal. Esta narrativa mapuche también fusiona vidas personales y acontecimientos históricos y los vuelve míticos a fin de contextualizar la historia local dentro de un proceso cíclico más amplio; distingue la historia chamánica mapuche de la historia chilena y conecta la memoria colectiva mapuche con las experiencias de los vivos. Al mitificar a Francisca como la restauradora del orden cósmico, los Mapuche de Millali recrean el lugar de su comunidad dentro de un nuevo contexto histórico. Un historiador oral, Alessandro Portelli (1998), argumenta que dichas 
narrativas deben tomarse con tanta seriedad como los sucesos "reales" pues son parte del proceso histórico. Cuando la familia de Francisca creyó que su espíritu podría renacer, me pidió que finalmente escribiera su "biblia".

Llevé el tocado y el anillo de Francisca de vuelta a Millali en diciembre de $20 \mathrm{II}$, luego de soñar que Francisca los pedía. Machi María explicó que para que el espíritu revivido de Francisca pudiera recuperar su pleno potencial necesitaba contar con sus objetos chamánicos y cortar su relación conmigo (un ser humano vivo que no se convertiría en machi).

“El [ex espíritu] püllü de Francisca estuvo en tu casa muchos años. Ahora se despertó y quiere recuperar sus objetos. Tienes que enterrarlos en su tumba. Habla con el püllü de Francisca. Su tumba está conectada con el Wenu Mapu [cielo mapuche] y ella escuchará lo que le digas. Dile, 'Gracias por dejarme cuidar de tus cosas. No me enfermes y no vuelvas en mis sueños porque yo devolví tus objetos. Cumplí con tu pedido."' [8 de diciembre de $20 \mathrm{II}$ ].

Con Aurora enterramos el tocado y el anillo de Francisca en un pequeño agujero en la lápida y oramos. Nunca más soñé con Francisca. Y cuando visité Millali en diciembre de 2012, tampoco nadie de la familia había vuelto a soñar con ella. Alegaron que Francisca había recuperado su poder y necesitaba tener su "biblia" terminada.

Al igual que la autobiografía de Sinek, la "artista de la memoria" del pueblo karo, la historia de Francisca era al mismo tiempo "una historia colectiva y un testimonio singular, una crónica literal de acontecimientos y una narrativa personal fabulada" (Steedly 2000: 8I4). La tensión entre la memoria y la identidad individuales (los objetos, los deseos y la "biblia" de Francisca) y la memoria y la identidad colectivas (el espíritu colectivo mítico filew, la versión mitificada de Francisca y la historia comunitaria) resulta evidente a lo largo de todo el proceso de olvidar y volver a recordar.Al deconstruir a Francisca, al deshacer su identidad individual y sus relaciones sociales con ella, $y$ al pedirme que escriba su biografía, los Mapuche obliteraron y olvidaron su historia individual controvertida en favor de la memoria comunitaria de todos los chamanes y de la identidad grupal. La individualidad y los rastros dejados por la vida de Francisca — sus objetos y vestimentas rituales - debían ser destruidos y su texto biográfico tenía que ser sometido a las narrativas históricas locales de desmemoria en ese momento político e histórico particular a fin de que prevaleciera la identidad colectiva. Tal como señaló Jennifer Cole (1998: 627), los recuerdos no son igualmente destacados todo el tiempo;y el proceso del recuerdo y la desmemoria está ligado al flujo de la vida social y a los intentos de las personas por controlarlo.

Además, la desmemoria colectiva de Francisca por parte de la comunidad tenía implicancias morales, sociales y emocionales. La desmemoria intencional de Francisca a su muerte ayudaba a que los deudos pudieran manejar su dolor, los escudaba de la brujería y protegía a los vivos de los muertos. El hecho de recordar su persona controvertida en ese momento habría proyectado el pasado conflictivo al presente, cosa que habría resultado perjudicial para los vivos. Sin embargo, no todos los rastros de la vida de Francisca fueron destruidos. Su hija me entregó algunos de sus objetos rituales para recordar a Francisca en el futuro porque sabía que, en algún momento venidero, su madre habría de ser recordada una vez más como individuo.

Luego de la muerte y el olvido de los individuos y sus historias, los espíritus chamánicos se transforman al fusionarse con el filew, son recordados otra vez colectivamente como individuos mitificados y luego son "reciclados" en los cuerpos de nuevas machi. Una vez restauradas la memoria mítica y la identidad colectiva de la comunidad y después de producirse cambios positivos que les aseguraron protección contra la brujería, los habitantes de Millali volvieron a individualizar e historizar el espíritu de Francisca, diferenciándola del filew genérico del cual ella había pasado a formar parte luego de su muerte. Marc Augé (2004) y Paul Ricoeur (2006) han argumentado que el olvido es una precondición necesaria para comprender y recordar el pasado y, también, para vivir plenamente el presente. Pero para los Mapuche, el pasado no se olvida sino que se controla, se deja a un lado y transforma antes de volver a emerger $y$ encarnarse en el presente y el futuro.

Por último, la vida, la muerte y el renacimiento potencial de Francisca les brindaron a los miembros de la comunidad una narrativa que 
borró el conflicto del pasado y justificó los cambios positivos ocurridos en ellos. Al recordar a Francisca y narrar su historia a través de temporalidades chamánicas, los habitantes de Millali intentan tener control sobre su presente y su futuro. Al cuestionar su historia traumática mencionando los poderes espirituales superiores de los Mapuche, esperan alcanzar igualdad y reconocimiento histórico. El modo en que Francisca es recordada y reincorporada a su comunidad trasciende tanto su vida como su muerte e ilumina la manera en que los habitantes de Millali imaginan y reescriben el pasado y el presente para las generaciones venideras.

Sin embargo, el espíritu chamánico reindividualizado de Francisca no era el que ella tenía en vida. Esta nueva versión de Francisca, mitificada, rehistorizada y despojada de sus cualidades ambiguas, era la que sería recordada colectivamente. Estos procesos aparentemente contradictorios del recuerdo y la desmemoria, de colectivizar e individualizar pueden cambiar u operar en forma simultánea o cíclica en momentos histórico-políticos importantes en el tiempo lineal.

\section{LA LECCIÓN DE ESCRITURA DE LAS MACHI: ALFABETIZACIÓNY CONCIENCIA HISTÓRICA}

Mi enfoque sobre la "biblia" de Francisca brinda una nueva comprensión acerca del rol de la palabra escrita en las alfabetizaciones chamánicas y de la biografía chamánica en la producción histórica indígena. He señalado que las machi expanden nuestros conceptos de alfabetización y temporalidades indígenas vinculando las biblias con la memoria mapuche individual y colectiva, con experiencias chamánicas de colonización, evangelización y mestizaje, y con ideas controvertidas sobre continuidad histórica, muerte y renacimiento. Los medios alternativos y los modos de identificación personal ocupan un lugar destacado en los procesos mapuche de reconstitución de una "vida" viable ante pérdidas y cambios traumáticos. Las narrativas biográficas chamánicas mapuche no sólo son los medios a través de los cuales la historia individual se convierte en mito colectivo y viceversa sino que también sirven para el renacimiento chamánico, que permitió brindarle a la comunidad de Francisca una transformación y continuidad estructurales; en otras palabras, historia local.

La alfabetización chamánica, las "biblias" intertextuales y la transformación de la memoria de Francisca indican que tanto ella como los habitantes de Millali controlan activamente sus economías de alteridad. El poder chamánico no ha disminuido con el mestizaje, como tampoco experimentan los Mapuche una "falta de capacidad de accionar" ni el "colapso de la participación controlada en la diferencia" (Course 2013: 775). Por el contrario, Francisca manipulaba el alfabeto estratégicamente con objetivos chamánicos y para legitimar sus propias identidades mutables y el orden moral mapuche, todo dentro de un nuevo contexto de alfabetización. Los Mapuche constantemente revisan y transforman sus identidades, sus términos y significados, para encontrar sentido a sí mismos a lo largo del tiempo. Francisca participaba de una economía de la alteridad que incluía un cierto tipo de "apertura hacia el Otro blanco" pero a su manera, que no implicaba un amplio proceso de "intercambio simbólico que atraviesa [atravesaba] límites ontológicos, cosmológicos y sociopolíticos" (Viveiros de Castro 1996: 189-190) para definir y constituir identidades colectivas.

La identidad champuria se encuentra en el centro de la forma de alfabetización chamánica de Francisca y de su habilidad para transformar eficazmente un texto sagrado no mapuche en un objeto chamánico animado. Sus poderes y habilidades especiales creaban, naturalmente, diversas tensiones dentro de su comunidad mapuche, al tiempo que aseguraban su legado en la comunidad. Estos efectos y las numerosas variedades de "biblias" que incorporan y animan las tradiciones textuales occidentales dentro de la cultura mapuche, su significado, su falta de anclajes temporales y sus múltiples vectores de utilización están todos vinculados con la identidad champuria de Francisca. También ofrecen una perspectiva más amplia sobre indigeneidad y colonialismo. Irónicamente, fue la cualidad champuria de Francisca la que le permitió promover esta forma más amplia y sorprendentemente menos occidental de temporalidad y conciencia histórica. Francisca logró rebatir las acusaciones de su awingkamiento (convertirse en alguien de afuera) y brujería interpretando su chamanización de la Biblia y la alfabetización como una forma de mediación entre las 
diferentes realidades para el bienestar colectivo. En el proceso, ella indigenizó biblias, alfabetos y su propia identidad como una mediadora machi mapuche.

La vida, la muerte y el renacimiento potencial de Francisca Kolipi muestran que podemos ampliar nuestra comprensión sobre la capacidad de accionar y la conciencia histórica si disolvemos las barreras conceptuales entre vivos y difuntos, entre actores humanos y espirituales. Los espíritus pueden convertirse en agentes históricos eficaces (Fausto y Heckenberger 2007: 14) si dejamos margen para la existencia de múltiples mundos y experiencias que vayan más allá de las intenciones de los autores, que excedan los límites del archivo y que reconozcan nuevas formas de compromiso místico entre espíritus y textos. Los no Mapuche a menudo ven la capacidad espiritual de accionar como una creencia irracional y las "biblias" místicas mapuche como objetos fetiche premodernos. Pero si cuestionamos la dicotomía de la oralidad y la alfabetización, si definimos la escritura como una forma de inscripción gráfica con una función performativa y no como un texto alfabético, y si vemos los textos como objetos rituales imbuidos de poder sagrado, surge entonces un nuevo panorama.

Francisca era una persona alfabetizada de tal manera que sus palabras siempre tenían un doble significado. Cuestionaba las percepciones sobre la escritura como un discurso del poder colonial, aunque su "biblia" permanece parcialmente arraigada dentro del discurso de alfabetización dominante. Dado que la permanencia del alfabeto era ya parte de la memoria y la historia mapuche, Francisca lo utilizaba como un medio nuevo a través del cual ella y otros Mapuche pudieran apropiarse del poder wingka de la palabra escrita y propagar las historias orales y el poder chamánico en un contexto nuevo. Al imbuir el alfabeto con sus poderes chamánicos, Francisca obtenía control sobre la forma, su significado y uso, creando diseños gráficos que guardaban su poder chamánico y las representaciones narrativas de su vida, $y$ creando un objeto animado que pudiera ser usado performativamente para hacer circular su poder después de su muerte. Además, Francisca me entrenó (a mí, la escritora champuria) en la práctica chamánica para que las palabras que yo escribiera también tuvieran un doble significado. Yo produje tanto un texto académico como un objeto animado que portaría su identidad champuria y su poder chamánico más que los de la historiografía positivista.

Por otro lado, la "biblia" de Francisca amplía y cuestiona los conceptos mapuche sobre historia, lo sagrado y las "biblias" mapuche en sí. El pedido que me hizo Francisca para que yo escribiera sobre su vida conflictiva en la comunidad, tal como la describió en un momento particular de su pasado, era importante para ella, pero la narrativa cuestionaba la historia colectiva y las ideas de continuidad histórica de la comunidad más amplia al relatar la historia mitificada de Francisca en el presente.A través de mi escrito académico sobre Francisca, se haría evidente la discrepancia entre la historia etnográfica de Millali en diferentes momentos en el tiempo - una serie discontinua de presentes que ahora pertenecían en su totalidad al pasado- y la etnografía actual en la que la comunidad crea una narrativa mitificada continua sobre el pasado a partir del presente. ¿Qué harían los habitantes de Millali cuando se vieran confrontados con la naturaleza construida de estas diferentes modalidades del pasado? ¿Acaso las narrativas anteriores sobre supuestas brujerías y conflictos en la comunidad recogidas entre 1991 y 1996 cuestionarían su nueva versión mitificada e interferirían con su renacimiento chamánico?

Alejo Huenchuñir, cuñado de Francisca, se rió de mis preguntas."Esto es lo que la gente decía en su momento. Pero ahora pensamos distinto.Anota todo en tu libro. Francisca tomará lo que quiera y otros pueden leer la historia. Cumple con tu promesa a Francisca. Sólo entonces quedarás libre" (8 de enero de 20/2). Alejo creó una discontinuidad histórica narrativa entre el presente y el pasado conflictivo de la comunidad, mientras que al mismo tiempo mantenía la continuidad histórica con los aspectos positivos del pasado: la fusión de las identidades y poderes chamánicos de Francisca y Rosa y mi promesa a largo plazo a Francisca. Mi etnografía sobre la práctica y la historia de vida individualizada de Francisca, tal como ella la relató entre 1991 y 1996, constituía mi compromiso personal con ella, compromiso que yo debía cumplir para permitir que el espíritu de Francisca se desvinculara plenamente de mí y se convirtiera en un espíritu machi autónomo. Y el reconocimiento colectivo de este espíritu como la fusión mitificada de los poderes de Rosa y Francisca y su impacto positivo en la comunidad era 
lo que formaría parte de la historia comunitaria y le permitiría renacer en el cuerpo de una nueva machi.

La gente de Millali no estaba preocupada por la "veracidad" de los acontecimientos y las fechas sino por una verdad moral más amplia expresada a través de su memoria y a través de la "biblia" de Francisca." Mi rol de antropóloga/ayudante del ritual transformó la manera en que Millali narraba la historia de la comunidad y cambió las percepciones mapuche sobre el chamanismo y la escritura. Mi "biblia" analizaría por qué la historia de Francisca se volvía a contar de una manera y no de otra e incluiría la historia de la producción de estas narrativas. El hecho de poner en un texto la narrativa oral chamánica mitificada junto con la historia de su producción y los detalles de la biografía de Francisca significaba que los habitantes de Millali deberían ahora relacionarse en simultáneo con múltiples narrativas del pasado, cada una con su propia agenda.

Las identidades mutables de las machi les permiten crear nuevas formas de comprensión que transforman sus memorias encarnadas del pasado y abren la posibilidad de un futuro viable. Los marcos temporales de las machi basados en la fluida relación entre el pasado, el presente y el futuro cuestionan los estudios contemporáneos sobre la memoria que equiparan básicamente el tiempo con las modalidades del pasado. Los estudiosos han definido la antropología de la historia en "cómo se conoce, entiende y representa el pasado en las sociedades del mundo" (cf. Palmie y Stewart 20I3) y analizaron fenómenos como los de los médiums de Madagascar que encarnan el pasado al ser poseídos por espíritus que comentan sobre el presente (Lambek 2003). Francisca, en cambio, manipulaba ritualmente el poder que emerge de las biblias y de los documentos oficiales para ver y revivir el pasado, cambiar la historia y construir un futuro mejor para su comunidad. Las machi también se oponen a la tendencia en la antropología de que "los futuros están reemplazando al pasado como un reservorio cultural" (Piot 20 10: 16) al establecer continuamente nuevas relaciones con el tiempo. Las temporalidades chamánicas recurren a las técnicas dinámicas de recordar y olvidar, así como a narraciones sobre historias de vida, muerte y renacimiento, y las proyectan en textos sagrados. Al hacer esto, los Mapuche ven el futuro como algo en parte conocido, anticipado y manipulado por las machi. Francisca seleccionó momentos del pasado y con creatividad recurrió a la Biblia como un objeto textual para crear "lo que sucedería" y lograr el renacimiento chamánico. El futuro toma la forma del pasado al transformarse por nuevos medios de expresión y las utopías soñadas en el presente. Sin embargo, alcanzar realmente un futuro utópico es algo incierto y a menudo cuestionado (cf. Biersack I991). Si el espíritu de Francisca no regresa, el desvanecimiento de este futuro utópico será atribuido a una falla moral, suya y de la comunidad. Si su espíritu regresa, algunos Mapuche utilizarán el texto sagrado de Francisca para cambiar y revivir el pasado a través de realidades y esperanzas del presente y para proyectarse a sí mismos y a sus espíritus en el futuro.

Agradecimientos: Agradezco el financiamiento del Harvard Radcliffe Institute for Advanced Study, el National Humanities Center y el School of Advanced Research. Estoy en deuda con todos los Mapuche de las comunidades de Millali, Imilco, Chihuimpilli, Nahuelhual, y Huenchual que conversaron conmigo sobre sus percepciones de tiempo e historia, textos y chamanismo y sobre todo con la machi Francisca Koilpe Kurin. También agradezco los comentarios de Olivier Allard, James Brooks, Michael Brown, Manduhai Buyandelger, Andrés Cuyul, Luis Cárcamo Huechante, Andrés Cuyul, Carlos Fausto, David Frankfurter, Gaston Gordillo, Laura Graham, Jean Jackson, Tanya Luhrmann, Bruce Mannheim, André Menard, Juan Ñanculef, Suzanne Oakdale, Daniela Peluso, Eduardo Rapiman, Douglas Rogers, Fernando Santos Granero, Rosalind Shaw, Gary Urton, Rebecca Walkowitz, y tres comentaristas anónimos.

\section{NOTAS}

I Webb Keane argumenta que los objetos textualizados pueden "reforzar la autoridad de los oficiantes brindándoles una posición trascendental desde donde dirigir la palabra" (2007: I5).

2 Los estudiosos han investigado este tema analizando el mito y las etnohistorias (Hill 1988, 2009; Turner 1988), la narrativa (Basso 1995, Fausto 2002, Oakdale 2005), el ritual (Conklin 1995, Graham 1995, Taylor 1993, Wright 1998), el paisaje (Santos Granero 1998, Vidal 2000), el parentesco (Gow $200 \mathrm{I}$ ) y la historicidad (Fausto y Heckenberger 2007, Taylor 2007, Whitehead 2003).

3 Varios autores argumentan que las comprensiones indígenas de las identidades transformadoras establecidas a través de la comensalidad, la cordialidad y la perspectiva compartida 
son el resultado de una moralidad compartida y conducen a esta (Course 201 I, Londoño Sulkin 2005, Overing y Passes 2000, Vilaça 2005, Viveiros de Castro 1998).

$4 \quad$ Los Jíbaro de la Amazonía también ven la crianza más que la transferencia de sustancia corporal como lo que constituye la relación parental (Taylor 2007: 19).

5 Thomas Abercrombie (1998) ha estudiado la manera en que el discurso oral se convierte en documentación a través de "vías de memoria y poder" y puede escribirse sobre papel y sobre la tierra.

6 Ver también Course $201 \mathrm{I}$ sobre el proceso mapuche de cómo terminar con el difunto.

7 El estudio de las representaciones del pasado como formas culturales en circulación social no "se ocupa en sí de la objetividad, precisión e imparcialidad de los relatos locales" (Hirsch y Stewart 2005: 268). Se ocupa, en cambio, de "la inversión política y cultural en dichos relatos y en la labor realizada por estos dentro de entornos sociales identificables, incluyendo las estructuras institucionales que aseguran la aceptabilidad contextual de algunos de esos relatos como representaciones 'veraces' del pasado 'real'" (Palmié 2010: 375).

\section{BIBLIOGRAFÍA}

Abercrombie, T. 1998. Pathways of Memory and Power: Ethnography and History among an Andean People. Editorial University of Wisconsin, Madison.

Augé, M. 2004. Oblivion. Editorial University of Minnesota, Minneapolis.

Bacigalupo, A. 1995. "El rol sacerdotal de la machi en los valles centrales de la Araucanía”. En: Modernización o sabiduría en tierra mapuche?, editado por A. Marileo, A. Bacigalupo, R. Salas, R. Curivil, C. Parker y A. Saavedra, pp. 5I-98. Ediciones San Pablo, Santiago.

---- 200I. La Voz del Kultrun en la Modernidad: Tradición y Cambio en la Terapéutica de Siete Machi Mapuche. Editorial Universidad Católica de Chile, Santiago.

---- 2003. "Rethinking identity and feminism: contributions of mapuche women and machi from southern chile". Hypatia I8(2):32-57.

---- 2004a. "The mapuche man who became a woman shaman: selfhood, gender transgression, and competing cultural norms". American Ethnologist 3I (3):440-457.

---- 2004b. "Ritual gendered relationships: kinship, marriage, mastery, and machi modes of personhood". Journal of Anthropological Research 60(2):203-229.

----2 2005. "The Creation of a Mapuche Sorcerer: Sexual Ambivalence, the Commodification of Knowledge, and the Coveting of Wealth". Journal of Anthropological Research 6I(3):3 I7-336.

----2 2007. Shamans of the Foye Tree: Gender, Power, and Healing among the Chilean Mapuche. Editorial University of Texas,Austin.

----2008. "The re-invention of mapuche male shamans as catholic priests: legitimizing indigenous co-gender identities in modern Chile". En: Native christians: Modes and efects of christianity among indigenous peoples of the americas, editado por R.Wright y A.Vilaca, Pp. 89-108. Editorial Ashgate, Aldershot.
---- 2010. "The life, death, and rebirth of a mapuche shaman: remembering, forgetting and the willful transformation of memory". Journal of Anthropological Research 66(I): 97-II9.

---2 2013. "Mapuche struggles to obliterate dominant history: mythohistory, spiritual agency, and shamanic historical consciousness in Southern Chile". Identities: Global Studies in Culture and Power 20(1): 77-95.

---- 2016. Thunder Shaman: Making History with Mapuche Spirits in Chile and Patagonia. University of Texas Press, Austin.

Basso, E. 1989. "Kalapalo Biography: Psychology and Language in a South American Oral History". American Anthropologist 91 (3):55I-569.

---- 1995. The Last Cannibals:A South American Oral History. Editorial University of Texas, Austin.

Bauman, R. 2004. A World of Others Words: Cross-Cultural Perspectives on Intertextuality. Editorial Blackwell, Malden.

Bengoa, J. 1999. Historia de un Conflicto: el Estado y los Mapuches en el Siglo XX. Editorial Planeta/Ariel, Santiago.

Benjamin, W. 1982 [1940]. "Theses on the philosophy of history". En: Illuminations, traducido por H. Arendt, pp. 253-264. Editorial Schocken, New York.

Biersack, A. 1991. "Prisoners of time: Millenarian praxis in a melanesian valley". En: Clio in Oceania: Toward a Historical Anthropology, editado por A. Biersack, Pp. 23I-296. Editorial Smithsonian Institution, Washington DC.

Brown, M. 1991. "Beyond resistance:A comparative study of utopian renewal in Amazonia”. Ethnohistory 38(4):388-4I3.

Cárcamo-Huechante, L. 20II. "The long history of indigenous textual cultures:A response". Textual Cultures 6(2): I42-146.

Cárcamo-Huechante, L., H. Nahuelpan Moreno, H. Huinca Piutrin, P. Mariman Quemenado, M. Mora Curriao, J. Quidel Lincoleo, E. Antileo Baeza, F. Curivil Bravo, S. Huenul Colicoy, J. Millalen Paillal, M. Calfio Montalva, J. Pichinao Huenchuleo, E. Paillan Coñoepan y A. Cuyul Soto. 20I2.Ta Iñ Fijke Xipa Rakizuameluwün: Historia, Colonialismo y Resistencia desde el País Mapuche. Editorial Colectivo de Historiadores Mapuche, Temuco. Chile.

Chakrabarty, D. 2000. Provincializing Europe: Postcolonial Thought and Historical Difference. Editorial Princeton University, Princeton.

Cole, J. 1998. "The work of memory in Madagascar". American Ethnologist 25(4):610-633.

Comaroff, J. y J. Comaroff.199I. Of Revelation and Revolution, vol. I: Christianity, Colonialism, and Consciousness in South Africa. Editorial University of Chicago, Chicago.

Conklin, B. 1995. "Thus are our bodies, thus was our custom": Mortuary cannibalism in an amazonian society". American Ethnologist 22(1):75-101.

Connerton, P. 1989. How Societies Remember. Editorial Cambridge University, Cambridge.

Course, M. 20I I. Becoming Mapuche: Person and Ritual in Indigenous Chile. University of Illinois Editorial, Urbana.

---- 2013. "The clown within: Becoming white and mapuche ritual clowns". Comparative Studies in Society and History 55(4):77I-799. 
Crow, J. 2010. "Negotiating inclusion in the nation: Mapuche intellectuals and the chilean state". Latin American and Caribbean Ethnic Studies 5(2):131-152.

De la Cadena, M. 2000. Indigenous Mestizos: The Politics of Race and Culture in Cuzco, Peru, 1919-1991. Editorial Duke University, Durham, NC.

Delrío, W. 2005. Memorias de Expropiación: Sometimiento e Incorporación Indígena en la Patagonia 1872-1943. Editorial Universidad Nacional de Quilmes, Buenos Aires.

EI Meteoro de los Angeles 1869. El Meteoro de los Angeles, June 19,4(I44).

Engelke, M. 2003. "The book, the church, and the "incomprehensible paradox": Christianity in african history". Journal of Southern African Studies 29(I):297-306.

Erikson, P. 2004."Chamanisme, écriture et ethnopolitique”. L'Homme I7I-I72: 525-528.

Erize, E. 1960. Diccionario Comentado Mapuche-Español: Araucano, Pehuenche, Pampa, Picunche, Rancülche, Huilliche. Editorial Instituto de Humanidades, Universidad Nacional del Sur, Bahía Blanca.Argentina.

Fausto, C. 2002. "Faire le mythe: Histoire, récit et transformation en Amazonie". Journal de la Societé des Americanistes 88:69-90.

Fausto, C. y M. Heckenberger. 2007. "Indigenous history and the history of Indians". En: Time and memory in indigenous amazonia: Anthropological perspectives, editado por C. Fausto y M.Heckenberger, pp. I-43. Editorial University of Florida, Gainesville.

Foerster, R. 1983. Martín Painemal: Vida de un Dirigente Mapuche. Ediciones Grupo de Investigaciones Agrarias (GIA), Santiago.

---- 1996. “Utopías indígenas: El caso huilliche”. La Época 65:20-21.

Gerbhart-Sayer, A. 1985. The Cosmos Encoiled: Indian Art of the Peruvian Amazon. Ediciones Center for Inter-American Relations, New York.

Gill, S. 1985. "Nonliterate traditions and holy books: Toward a new model". En: The Holy Book in Comparative Perspective, editado por F. Denny y R. Taylor, pp. 224-239. Editorial University of South Carolina, Columbia.

Gobierno de Chile. 20I I.Pueblos Originarios CASEN 201 I. Disponible en http://observatorio.ministeriodesarrollosocial.gob. $\mathrm{cl} /$ layout/doc/casen/Pueblos_Indigenas_Casen_20ll.pdf. Acceso 15 de octubre de 2013 .

Goldman, M. 20II. "Cavalo dos deuses: Roger Bastide e as transformações das religiões de matriz africana no Brasil". Revista de Antropologia 54(I):407-432.

Gordillo, G. 2003. "Shamanic forms of resistance in the argentine chaco: A political economy". Journal of Latin American Anthropology 8(3): 104-126.

Gow, P. 1990. "Could sangama read? The origin of writing among the piro of Eastern Peru". History and Anthropology 5:87103.

---- 200I. An Amazonian Myth and Its History. Editorial Oxford University, Oxford.
Graham, L. 1995. Performing dreams: Discourses of immortality among the xavante of Central Brazil. Editorial University of Texas, Austin.

Guzman-Gallegos, M. 2009. "Identity cards, abducted footprints and the book of san gonzalo: The power of textual objects in runa worldview". En: The occult life of things: Native amazonian theories of materiality and personhood, editado por F. Santos Granero, Pp. 2/4-234. Editorial University of Arizona, Tucson.

Hill, J. (ed.). 1988. Rethinking History and Myth: Indigenous South American Perspectives on the Past. Editorial University of Illinois, Urbana.

----2 2009 "History, power, and identity: Amazonian perspectives". Acta Historica Universitatis Klaipedensis XIX, Studia Anthropologica III:25-47.

Hirsch, E. y C. Stewart. 2005. "Introduction: Ethnographies of historicity”. History and Anthropology I6(3):26I274.

Hugh-Jones, S. 2010. “Entre l'image et l'ecrit: La politique tukano de patrimonialisation en Amazonie". Cahiers de Amériques Latines 63-64:195-227.

Keane, W. 2007. Christian Moderns: Freedom and Fetish in the Mission Encounter. Editorial Universityof California, Berkeley.

Kendall, L. \&J. Yang. N.d. Goddess with a Picasso Face: Art Markets, Collectors and Sacred Things in the Circulation of Korean Shaman Paintings. Unpublished MS, American Museum of Natural History and National Folk Museum of Korea.

Lambek, M. 2003. TheWight of the Past: Living with History in Mahajanga, Madagascar. Editorial Palgrave Macmillan, Basingstoke, UK.

Lévi-Strauss, C. 1955. “La leçon d'écriture”. En: Tristes Tropiques, pp. 312-324. Editorial Plon, Paris.

Lordoño Sulkin, C. 2005. "Inhuman beings: Morality and perspectivism among muinane people (Colombian Amazon)”. Ethnos 70(I):7-30.

Mallon, F. 2005. Courage Tastes of Blood: The Mapuche Community of Nicolas Ailio and the Chilean State, 1906-200I. Durham, NC: Editorial Duke University.

---- 2009. "El siglo XX Mapuche: Esferas públicas, sueños de autodeterminación y articulaciones internacionales". En: Movilizaciones indígenas en Chiapas y Araucanía, editado por C.Martínez Neira y M. E. Saavedra, pp. I55-190. Editorial Catalonia, Santiago.

Mariman, P., S. Caniuqueo, J. Millalén y R. Levil. 2006. Escucha Winka: Cuatro Ensayos de Historia Nacional Mapuche y un Epílogo sobre el Futuro. Lom Ediciones, Santiago.

Marx, K. 1977[ 1867]. Capital:A Critique of Political Economy, voll. Editorial Vintage, New York.

Menard, A. 2003. "Manuel Aburto Panguilef: De la república indígena al sionismo mapuche”. Nuke Mapu Working Papers Series 12. Disponible en http://www.mapuche.info, Acceso 15 october 2013.

----2010. “Sobre la biografía de Manuel Aburto Panguilef”. Trabajo presentado en el VI Congreso de Antropología, San Pedro de Atacama, October 25-29. 
Menard, A. y J. Pavez. 2005. "El Congreso Araucano: Ley, raza y escritura en la política mapuche”. Política 44:2 I I-232. Ocho Libros.

---- 2007. Mapuche y Anglicanos. Santiago, Chile: Editorial

Oakdale, S. 2005. “I Foresee My Life”:The Ritual Performance of Autobiography in an AmazonianCommunity. Editorial University of Nebraska, Lincoln.

Overing, J. y A. Passes. 2000."Introduction: Conviviality and the opening up of amazonian anthropology". En: The anthropology of love and anger:The aesthetics of conviviality in native Amazonia, editado por J. Overing \& A. Passes, pp. I-30.Routledge, Londres.

Palmié, S. 2010. "Slavery, historicism and the poverty of memorialization”. En: Memory: Histories, theories, debates, editado por S. Radstone \& B. Scwarz, Pp. 363-375. EditorialFordham University. Bronx.

Palmié, S. y Ch. Stewart. 2013. "For an anthropology of history". Trabajo presentado en I/2th Annual Meeting of the American Anthropological Association, Chicago, November.

Pavez, J. 2008. Cartas Mapuche: Siglo XIX. Editorial Ocho Libros, Santiago.

Perrin, M. 1986. "Savage points of view on writing". En: Myth and the imaginary in the new world, editado por E. Magaña \& P. Mason, pp. 2II-23I.Editorial Foris, Dordrecht.

Pels, P. 1998. "The spirit of matter: On fetish, rarity, fact, and fancy". En: Border fetishisms: Material objects in unstable spaces, editado por P. Spyer, pp. 91-121. Routledge, New York.

Piot, Ch. 20I0. Nostalgia for the Future:West Africa after the Cold War.Editorial University of Chicago, Chicago.

Platt, T. 1992. Writing, Shamanism and Identity or Voices from Abya-Yala. Editorial Oxford University, Oxford.

Portelli, A. 1988. "Uchronic dreams: Working class memory and possible worlds". Oral History 16(2):46-56.

Rappaport, J. 1998. The Politics of Memory: Native Historical Interpretations in the Colombian Andes. Editorial Duke University, Durham, NC.

Rappaport, J. y T. Cummins. 2012. Beyond the Lettered City: Indigenous Literacies in the Andes. Editorial Duke University, Durham, NC.

Richards, P. 2013. Raceand the Chilean Miracle: Neoliberalism, Democracy, and Indigenous Rights. Editorial University of Pittsburgh, Pittsburgh.

Ricoeur, P. 2006. Memory, History, Forgetting. Editorial University of Chicago, Chicago.

Salomon, F. y M. Niño-Murcia. 20II. The Lettered Mountain: A Peruvian Village's Way with Writing. Editorial Duke University, Durham, NC.

Santos Granero, F. 1998. "Writing history into the landscape: Space, myth, and ritual in contemporary Amazonia". American Ethnologist 25(2): I28-148.

---- 2009. "From baby slings to feather bibles and from star utensils to jaguar stones:The multiple ways of being a thing in the yanesha lived world". En: the occult life of things: Native amazonian theories of materiality and personhood, editado por F. Santos Granero, Pp. 105-127. Editorial University of Arizona, Tucson.
Silverstein, M. y G. Urban. 1996. Natural Histories of Discourse.Editorial University of Chicago, Chicago.

Smith, E. 1855. The Araucanians; or, Notes of a Tour among the Indian Tribes of Southern Chili. Editorial Harper and Brothers, New York.

Steedly, M. 2000."Modernity and the memory artist:The work of imagination in highland Sumatra, 1947-1995". Comparative Studies in Society and History 42(4):81 I-846.

Stoller, P. 1980. "The epistemology of sorkotarey: Language, metaphor and healing among the songhay". Ethos 8(2): || $7-|3|$.

---- 1995. Embodying Colonial Memories: Spirit Possession, Power, and the Hauka in WestAfrica.Routledge, New York.

Taylor, A.C. 1993. "Remembering to forget: Identity, mourning and memory among the Jivaro". Man 28:653-678.

---- 2007. "Sick of history: Contrasting regimes of historicity in the Upper Amazon". En: Time and memory in indigenous amazonia: Anthropological perspectives, editado por C. Fausto \& M. Heckenberger, Pp. 133-I68. Editorial University of Florida, Gainesville.

Taussig, M. 1987. Shamanism, Colonialism, and the Wild Man: A Study in Terror and Healing. Editorial University of Chicago, Chicago.

---- 1993. Mimesis and Alterity: A Particular History of the Senses. Routledge, New York.

Turner, T. 1988. "Ethno-ethnohistory: Myth and history in native south american representations of contact with western society". En: Rethinking history and myth: Indigenous south american perspectives on the past, editado por J. Hill, pp. 235-28I. Editorial University of Illinois, Urbana.

Vidal, S. 2000. "Kuwé duwákalumi: The arawak sacred routes of migration, trade, and resistance". Ethnohistory 47(34):635-667.

Vilaça, A. 2005. "Chronically unstable bodies: Reflections on amazonian corporalities". Journal of the Royal Anthropological Institute I I (3):445-464.

Viveiros de Castro, E. 1996. "Images of nature and society in amazonian ethnology". Annual Review of Anthropology 25: $179-200$.

---- 1998. "Cosmological deixis and amerindian perspectivism". Journal of the Royal Anthropological Institute 4(3):469-488.

Whitehead, N. 2003. "Histories and historicities in Amazonia". En: Histories and Historicities in Amazonia, editado por N.Whitehead, pp. 59-80. Editorial University of Nebraska, Lincoln.

Wright, R. 1998. Cosmos, Self, and History in Baniwa Religion: For Those Unborn. Editorial University of Texas, Austin. 